\begin{abstract}
THE EFFECT OF ACTIVE WORKSTATION USE ON MEASURES OF COGNITION, ATTENTION AND MOTOR SKILL

by Christina M. Ohlinger RD, LD
\end{abstract}

The purpose of this study was to assess participants' ability to perform tasks requiring attention, short term memory, and simple motor skill while sitting, standing or walking at an active workstation. Fifty participants completed the Stroop Color Word test (SCWT), Auditory Consonant Trigram test (ACTT), and Digital Finger Tapping test (DFTT) while sitting, standing and walking $1.6 \mathrm{~km} / \mathrm{h}$ at an active workstation. A significant difference was found for DFTT, but not ACTT or SCWT. Examination of the linear contrasts and post-hoc means comparison tests revealed significant differences in DFTT scores between sitting and walking $(\mathrm{t}=2.39$ (49) $P<0.02)$ and standing and walking $(\mathrm{t}=2.28(49) P<0.03)$. These results indicate that adding the walking task to the ACTT and SCWT conditions results in no decrement in performance on these tasks. Conversely, adding the walking task to the DFTT condition results in reduced performance on the DFTT task. 


\title{
THE EFFECT OF ACTIVE WORKSTATION USE ON MEASURES OF COGNITION, ATTENTION AND MOTOR SKILL
}

\author{
A Thesis \\ Submitted to the \\ Faculty of Miami University \\ in partial fulfillment of \\ the requirements for the degree of \\ Master of Science \\ Department of Kinesiology and Health \\ by \\ Christina M. Ohlinger RD, LD \\ Miami University \\ Oxford, Ohio \\ 2009 \\ Advisor: $\quad$ Ronald H. Cox, $\mathrm{PhD}$ \\ Reader: $\quad$ William P. Berg, PhD \\ Reader: $\quad$ Thelma S. Horn, PhD
}




\section{Table of Contents}

\section{Chapter}

I. Introduction 1

II. Methods 3

$\begin{array}{ll}\text { Participants } & 3\end{array}$

Study Design $\quad 4$

$\begin{array}{ll}\text { Test Battery } & 4\end{array}$

Experimental Apparatus $\quad 5$

$\begin{array}{ll}\text { Study Procedures } & 6\end{array}$

$\begin{array}{ll}\text { Statistical Analyses } & 6\end{array}$

III. Results 6

Descriptive Characteristics $\quad 6$

$\begin{array}{ll}\text { Preliminary Analyses } & 7\end{array}$

$\begin{array}{ll}\text { Main Study Analyses } & 7\end{array}$

$\begin{array}{llr}\text { IV. Discussion } & 8\end{array}$

$\begin{array}{ll}\text { Strengths and Limitations } & 9\end{array}$

$\begin{array}{ll}\text { Conclusions } & 9\end{array}$

IV. References 11 


\section{List of Tables}

Table

1. Characteristics of participants 6

2. Descriptive statistics (means and standard deviations) for all tests 7 across all experimental conditions.

3. Results of main study analyses (one-way ANOVAs) 


\section{The Effect of Active Workstation Use on Measures Of Cognition, Attention and Motor Skill}

\section{INTRODUCTION}

The economic cost of chronic diseases in the United States was estimated to be nearly 1 trillion dollars in the year 2000. ${ }^{1}$ One-half of that amount was attributed to costs associated with coronary heart disease, diabetes, and obesity. ${ }^{1}$ While the economic costs associated with treating these diseases is burdensome, the consequences of these diseases to the individual can be devastating. For example, type II diabetes can—and often does—lead to retinal deterioration, heart disease, renal disease, and loss of limbs to amputation. ${ }^{2}$ Booth et al. write that our society is at war with chronic disease and state that "with the possible exception of diet modification, we know of no single intervention with greater promise than physical exercise to reduce the risk of virtually all chronic diseases simultaneously."1 Despite a public health focus on consistent participation in physical activity, ${ }^{3,4}$ in 2005 just $49.1 \%$ of the population of U.S. adults met the minimum recommendations of 30 minutes of moderate intensity physical activity on most days of the week or 20 minutes of vigorous intensity physical activity on three days of the week. ${ }^{5}$

More than 20 years ago evidence began to accrue that showed physical activity that was insufficient to improve physical fitness as measured by maximal oxygen consumption was sufficient to produce changes in one's health risk profile. ${ }^{6}$ This literature also showed that those who would make the greatest gains in improving their health risk profile were those who were most sedentary and then adopted a physically active lifestyle. ${ }^{7}$ The duration and intensity of physical activity needed to improve health continues to be debated in the literature. ${ }^{8}$ However, physical activity recommendations from the American College of Sports Medicine (ACSM) and the Centers for Disease Control and Prevention (CDC) now recognize the value of accumulating moderate-intensity activity through the activities of daily living such as house cleaning, gardening, and the like. ${ }^{9,10}$ The CDC has gone one step further by acknowledging that any activity is better than no activity. ${ }^{10}$ There is a further shift in the literature seeking to clearly define and quantify sedentary behavior. The focus is on uncoupling low-intensity physical activity from sedentariness (i.e., sitting). Though the term sedentary is ubiquitous in the physical activity literature, Pate ${ }^{11}$ notes that sedentary behavior is rarely measured in scientific studies of activity. Rather, those who fail to meet physical activity guidelines put forth by entities such as the CDC and ACSM are described as being sedentary. Thus, if sedentariness is defined as 
absence of activity, physical activity can be viewed on a continuum rather than as the mere presence or absence of moderate/vigorous-intensity physical activity. This issue is not merely a squabble over a definition of the term sedentary. There is growing evidence that true sedentariness may be pathogenic in and of itself regardless of whether or not one meets the CDC and ACSM guidelines for physical activity.

Healy, Dunstan and colleagues ${ }^{12}$ have brought the issue into focus with their study of television viewing time. Television viewing time has been used to quantify the effects of extended sitting time. More time spent watching television is correlated with increased health risks and has been found to be associated with metabolic risk. Most importantly, even people who meet the current $\mathrm{CDC}^{10}$ and $\mathrm{ACSM}^{9}$ guidelines of the equivalent of 30 minutes of moderate-intensity activity 5 days per week are at greater health risk if they spend a large part of the day in a sedentary state. ${ }^{12}$ Specifically, a positive dose-response relationship was found between television viewing and waist circumference, systolic blood pressure, and 2-hour plasma glucose in adult men and women. Additionally, unfavorable dose-response relationships for fasting plasma glucose, triglycerides, and HDL-C were found in women.

The work of Bey and Hamilton ${ }^{13}$ supports the notion that there are adverse consequences to physical inactivity that can be alleviated by maintaining daily low-intensity physical activity. One of the adverse consequences of physical inactivity is the downregulation of the enzyme lipoprotein lipase (LPL). ${ }^{14}$ Loss of LPL activity has been found to be associated with health risks related to obesity, type II diabetes, and coronary heart disease. ${ }^{15}$ Hamilton, Hamilton and Zderic ${ }^{16}$ propose that accumulation of low- to moderate-intensity ambulatory activity maintains LPL activity and thus reduces the metabolic risks that would accrue as a result of being sedentary. Thus, reducing the time people spend doing activities that do not require any physical activity has the potential to positively impact health.

For many people, occupational pursuits contribute to the time spent in sedentary activities. More than 58 million people in the United States are employed in low-activity occupations. ${ }^{17}$ To combat sedentariness in desk-bound workers, work-based physical activity programs have been implemented that focus on increasing time spent in physical activity. Green and colleagues ${ }^{18}$ reported on a work-based physical activity intervention that encouraged employees to set and achieve weekly goals for physical activity. The program included promotional materials, team support, and incentives including a free pedometer. At the six month 
follow-up, physical activity levels were not significantly different from what they were at baseline. The participants in the Green et al. study identified busy work and home schedules as factors that prevented them from increasing their activity levels. This finding is consistent with the results found by Kruger and colleagues ${ }^{19}$ in their analysis of data from the 2004 HealthStyles survey. They found the reasons most commonly cited for not participating in worksite wellness programs were lack of time during the workday, lack of time before work, and lack of time after work. Given that people find it difficult to find time for activity outside of work, one possible approach is to increase low intensity physical activity during the workday.

The implementation of active workstations in the work environment is an innovation that may be used to increase low intensity physical activity in the workplace. ${ }^{20}$ One type of commercially available active workstation integrates a treadmill with a height-adjustable desk. This concept—-pioneered by Edelson and Danoff ${ }^{21,22}$ and recently revived by Levine ${ }^{20}$ —allows workers to spend a portion of their day walking while working. In an early study with a small number of participants, Edelson and Danoff reported no decrement in typing speed with an active workstation. ${ }^{22}$ However, John et al. report a 9\% decrement in typing speed with simultaneous performance of walking at $1.6 \mathrm{~km} / \mathrm{h}$ and typing. ${ }^{23}$ Although the results reported by John et al. are consistent with predictions from dual-task research using treadmill walking as a variable, ${ }^{24-27}$ it remains unclear as whether the decrement in performance is due to interference between the two motor tasks or if attention demanding cognitive factors play a role.

Walking while working will require workers to perform two or more tasks at one time, such as walking while talking, keyboarding, and reading. In addition to these motor tasks, workers will also be simultaneously engaged in cognitive tasks, such as calculating, comprehending, interpreting, and problem solving. The tests used in this study were chosen to address fundamental aspects of motor and cognitive function.

The purpose of this study was to assess the ability of participants to perform tasks requiring attention, short term memory, and simple motor skill while sitting, standing or using an active workstation. I hypothesized that if walking were added to the tasks requiring attention, short term memory, and simple motor skill, then there would be a decrement in performance in these tasks

\section{METHODS}

\section{Participants}


Fifty participants who are employees of Miami University were recruited. Potential participants were excluded if they were uncomfortable walking at slow speeds, if their physician had ever told them not to walk, if they required an assistive device to walk, if they had or suspected they had a balance disorder, or if they weighed more than 150 kilograms. All participants provided written informed consent and the Miami University Institutional Review Board approved the study.

\section{Study Design}

A within participants experimental design was used to compare study participants' ability to perform two cognitive and one motor task under three experimental conditions: while seated, while standing, and while walking on an active workstation. All participants completed all three conditions. Individual participants were randomly assigned to one of six possible orders for completion of the sit, stand, and walk conditions in order to minimize the confounding effects of test order and fatigue. In addition, the order in which the three tests were presented was counterbalanced across participants.

\section{Experimental Apparatus}

The active workstation used in this study is a commercially available product (Details, Grand Rapids, MI) that consists of an electric height adjustable desk with an integrated treadmill. The height of the desk is adjustable from 56 to 116 centimeters above the deck of the treadmill and the desktop is 99 centimeters wide by 69 centimeters deep. While the treadmill speed is adjustable from 0.48 to $3.20 \mathrm{~km} / \mathrm{h}$ on this device, all participants were tested at a speed of 1.60 $\mathrm{km} / \mathrm{h}$. This desk was used for the three postural conditions employed in this study: sitting, standing, and walking. In the sitting condition, a 1.2 meters by 1.2 meters wooden platform was placed over the treadmill and a standard office chair was placed on it. The chair was removed and the participant stood on the platform in the standing condition. In the walking condition, both the chair and platform were removed so the participant could walk on the treadmill.

\section{Test Battery}

Each participant completed three tests under each of the experimental conditions to assess divided attention, short term auditory verbal memory, selective attention, and simple motor skill while sitting, standing, and walking. The Auditory Consonant Trigram test (ACTT) was used to assess divided attention and short term auditory verbal memory. The ACTT has been found to be 
valid to assess these traits. ${ }^{28}$ For this test, the participant was presented with a consonant trigram (e.g., BCT) and was asked to recall the three consonants. There were two stages of this test. In the first, the participant was presented with five trials and asked to immediately recall the trigram. In the second, the participant was presented with 15 trials in which the consonant trigram was followed by a number that varied for each trial (e.g., QLX 109). The participant then counted backward by $3 \mathrm{~s}$ out loud from the number specified for a variable amount of time. This time was 3, 9, or 18 seconds. After counting, they were asked to recall the consonant trigram. Each participant completed a total of 20 trigrams while sitting, standing, and walking. The score was the number of correctly recalled consonants.

The Golden Stroop Color and Word test (SCWT) (Stoelting, Wood Dale, IL) was used to measure selective attention. The SCWT activates an automatic verbal interference by requiring the participant to override the reading response in favor of color naming. This test has been found to be a reliable and valid measure to identify differences in selective attention related to interference. ${ }^{29}$ This test consists of three sections. Each section has 100 items presented in five columns of 20 items each. Section one consists of the words red, green, and blue presented randomly and printed in black ink. Participants verbalized as many of these words as possible in 45 seconds. Section two contains blocks of four $X$ s printed in red, green, or blue ink and participants verbally identified the color of the print of as many items as possible in 45 seconds. Section three contains color words printed in an incongruent color-for instance the word red printed in blue or green ink. The participant's task was to verbally identify the color in which the word was printed rather than reading the word and to complete as many items as possible in 45 seconds. T-scores, which adjust for age and education, were calculated from the number of correctly identified items per page within 45 seconds. ${ }^{30}$ The participants completed each of the three sections while sitting, standing and walking.

The Digital Finger Tapping test (DFTT) was used as a measure of motor speed and motor control for which it has been found to be valid and reliable. ${ }^{31}$ This test uses a digital tapping apparatus (Western Psychological Services, Los Angeles, CA) that has a button the participant taps repeatedly with the index finger. The device records the number of taps beginning with the first depression of the button and displays this number at the end of each 10 second trial. Participants were instructed to place the "heel" of the hand on the desk top and avoid using the whole hand, wrist, or arm. Each participant performed six 10-second trials-in sets of three 
trials — with each hand while sitting standing, and walking. Participants alternated hands between sets, starting with the dominant hand. There was a 15-second rest period between trials. A score of at least 4 taps faster or slower than the next highest or lowest score was considered to be an outlier and that score was replaced by an alternate trial to make a total of six valid trials as described elsewhere by Russell and Starkey. ${ }^{32}$ The score recorded was the average number of taps for six valid trials for both hands.

\section{Study procedures}

All data were collected during a single 75-minute visit to the lab. Participants were oriented to the lab and completed a demographic questionnaire-for the purpose of describing the sample-that included self-reported height and weight, age, gender, job title, hours spent sitting each day, dominant hand, and number of days they exercise each week. Participants then completed all three experimental conditions in a pre-determined randomized order. The three tests were administered in random order after each experimental condition.

\section{Statistical analyses}

All data were collated and entered into an SPSS for Windows (v16) data file. Descriptive statistical analyses were conducted for purposes of data screening (e.g., identification of possible outliers, testing for linearity and normality). Inferential statistical analyses began with a series of mixed model ANOVAs to determine if there were any order effects in regard to both the sequence in which participants completed the three experimental conditions and in the order in which they completed the three tests. The main study hypotheses were tested with a series of one-way repeated measures ANOVAs. Statistical significance for all statistical analyses was set at $\mathrm{P}<0.05$.

\section{RESULTS}

\section{Descriptive characteristics}

Complete data were obtained from all 50 participants. Descriptive characteristics for the entire sample are presented in Table 1. 
Table 1: Characteristics of participants $(n=50)$

\begin{tabular}{|llcc|}
\hline Characteristic & Mean \pm SD & Minimum & Maximum \\
\hline Years of Education & $16.2 \pm 2.7$ & 12 & 20 \\
Age $($ years $)$ & $43.2 \pm 9.3$ & 23 & 60 \\
BMI $\left(\mathrm{kg} / \mathrm{m}^{2}\right)$ & $28.5 \pm 5.9$ & 18.5 & 47.1 \\
Work hours seated/day & $6.4 \pm 2.2$ & 2 & 12 \\
Exercise days/week & $3.1 \pm 2.0$ & 0 & 7 \\
\hline
\end{tabular}

\section{Preliminary Analyses}

I ran a series of 6 X 3 (Experimental Order by Experimental Condition) mixed model ANOVAs, with repeated measures on the second factor, to determine if the order in which participants completed the three experimental conditions affected their scores on the dependent variables (SCWT score ACTT score, DFTT score). In addition, a series of 3 X 3 (Test Order by Experimental Condition) mixed model ANOVAs were run to determine if the order in which the tests were administered affected participants performance on these tests. The results from these preliminary analyses revealed no significant main or interaction effects for either the order in which participants completed the experimental conditions or in the order in which they completed the three tests.

\section{Main Study Analyses}

Descriptive data for all tests across all experimental conditions are presented in Table 2. To test whether participants' scores on the three tests differed across the three experimental conditions, a series of one-way repeated measures ANOVAs were conducted. The results of these main study analyses (see Table 3 ) revealed no significant differences across the three experimental conditions (sitting, standing, and walking) in participants' scores on two of the three tests. However, a small yet significant difference in DFTT scores was found between the sitting, standing, and walking conditions. Examination of the linear contrasts and results from post-hoc means comparison tests revealed significant differences in DFTT scores between sitting and walking ( $\mathrm{t}=2.39$ (49) $P<0.02)$ and standing and walking $(\mathrm{t}=2.28$ (49) $P<0.03)$. No significant difference was found between the sitting and standing conditions. These results indicate that adding the walking task to the ACTT and SCWT tasks results in no decrement in 
performance on these tasks. Conversely, adding the walking task to the DFTT task results in reduced performance on the DFTT task.

Table 2: Descriptive statistics (means and standard deviations) for all tests across all experimental conditions.

\begin{tabular}{|lccc|}
\hline \multicolumn{1}{|c}{ Test } & \multicolumn{1}{c}{$\begin{array}{c}\text { Sit } \\
\text { Mean } \pm \text { SD }\end{array}$} & $\begin{array}{c}\text { Stand } \\
\text { Mean } \pm \text { SD }\end{array}$ & $\begin{array}{c}\text { Walk } \\
\text { Mean } \pm \text { SD }\end{array}$ \\
\hline $\begin{array}{l}\text { Auditory Consonant Trigram Test } \\
\text { (number of correctly recalled consonants) }\end{array}$ & $52.7 \pm 5.6$ & $53.3 \pm 5.4$ & $53.04 \pm 5.2$ \\
Stroop Color Word Test & $55.0 \pm 11.9$ & $54.8 \pm 10.7$ & $55.4 \pm 10.8$ \\
$\begin{array}{l}\text { (T-score) } \\
\text { Digital Finger Tapping Test }\end{array}$ & $57.2 \pm 8.4$ & $57.0 \pm 8.0$ & $55.8 \pm 8.0$ \\
(average number of taps with both hands) & & & \\
\hline
\end{tabular}

Table 3: Results of main study analyses (one-way ANOVAs)

\begin{tabular}{|llll|}
\hline \multicolumn{1}{|c}{ Test } & \multicolumn{1}{c}{ F (df) } & \multicolumn{1}{c|}{$\boldsymbol{P}$ value } & \multicolumn{1}{c|}{$\boldsymbol{\eta}_{\mathbf{p}}{ }^{\mathbf{2}}$} \\
\hline Auditory Consonant Trigram Test & $0.36(2,48)$ & $<0.70$ & $\mathrm{n} / \mathrm{a}$ \\
Stroop Color Word Test & $0.15(2,48)$ & $<0.86$ & $\mathrm{n} / \mathrm{a}$ \\
Digital Finger Tapping Test & $3.42(2,48)$ & $<0.04^{*}$ & 0.07 \\
\hline
\end{tabular}

*Significance level $\mathrm{P}<0.05$

\section{DISCUSSION}

The results of this study found that the addition of a low-intensity walking task results in a small yet significant $(\mathrm{P}<0.05)$ performance decrement on the DFTT task but results in no significant increase or decrease in performance on the SCWT task or the ACTT task. These findings suggest that the addition of low-intensity walking to the tasks that are primarily cognitive in nature do not have a negative effect on performance of the cognitive task. Conversely, adding low-intensity walking to a simple motor task does negatively affect performance on the simple motor task.

These results are in basic agreement with studies using dual-task protocols to evaluate the degree to which walking requires attention. ${ }^{24-27}$ That is, walking-while highly practiced-is not entirely automatic and depending on the type (motor or cognitive) and complexity of the task added to walking, decrements in performance may occur. We note that the above referenced 
studies involved faster walking speeds than did our protocol and we question to what degree speed of walking may have affected performance on both the cognitive and motor tasks employed in this study. Further, by asking participants to tap as rapidly as possible while walking at $1.6 \mathrm{~km} / \mathrm{h}$ a condition may have resulted wherein the participant was being forced to maintain two different rhythms simultaneously. There is support in the literature for the notion that maintaining two asynchronous rhythms with the hands may result in a performance decrement. ${ }^{33}$ In the case of walking and finger-tapping the participants were likely maintaining two asynchronous rhythms. This asynchrony may have placed additional demands on attention such that the participant unconsciously decreased their tapping speed in an attempt to bring the tapping and walking rhythms into harmony.

Prior research using walking at slow speeds at active workstations while performing the motor tasks of typing has published conflicting results. Edelson and Danoff ${ }^{22}$ found no decrement in typing when low-intensity walking was added to a typing task. Conversely, John et al. $^{23}$ found a $9 \%$ decrement is typing performance (average words per minute) when typing was added to a low-intensity $(1.60 \mathrm{~km} / \mathrm{h})$ walking task. The results of the current study are consistent with those of John et al. in regard to slowing in a motor task when combined with walking.

The results of the SCWT confirm the results of John et al. ${ }^{23}$ in that there was no significant difference in performance on the SCWT between the sitting and walking conditions. Further, this study extends the findings to a different population. Specifically, ours was a broader population (mean age of $43.2 \pm 9.3$ and an age range of 23-60) of employed workers. The assessment of interference between cognitive and motor tasks used the ACTT as the focal task. The ACTT has been found to be valid to assess divided attention and short term auditory and verbal memory and lends itself to use in the general population. ${ }^{28}$ The failure to find a significant difference on this task suggests that divided attention and short term auditory and verbal memory were not adversely affected by the addition of the low-intensity walking task.

\section{Strengths and Limitations}

A limitation of this study is that we tested participants at only one walking speed and not at a speed preferred by each individual. It is possible that a slower or faster preferred speed might have an effect on the observed performance decrement in DFTT. Also, the tasks used, though standardized, did not simulate actual office work. Lastly, the effects of practice may reduce or eliminate any performance decrement identified in this study. 
Strengths of this study include a larger, more age diverse, employed population. The number of participants tested provided statistical power to support the negative results on the SCWT and the ACTT. Further, it was sufficient to detect a small ( 2\%) performance decrement on the DFTT. However, the effect size is only small to medium suggesting other unidentified factors may be involved.

\section{Conclusions}

These results support the hypothesis in regard to a decrement in DFTT score when walking is added to the task. The hypothesis is not supported in regard to the ACTT and SCWT scores. This is an important finding as it suggests that walking while working will not interfere with cognitive tasks and further supports the notion that the decrement reported for typing by other investigators has its origin in motor factors. The results of this study suggest that more complex tasks, such as typing, might be affected more extensively by walking and cannot be readily dismissed. Observation of approximately a $2 \%$ decrement in a simple finger tapping task while insignificant in a practical sense has meaning when viewed in the context of the $9 \%$ decrement found by John et al. ${ }^{23}$ in typists averaging 40 adjusted words per minute. This suggests that motor decrements may be even greater at faster typing speeds. The absence of a reported decrement by Edelson and Danoff ${ }^{22}$ may be due to either a lack of statistical power or a training effect. Future research should focus on assessing factors that can ameliorate performance decrements. Consideration should be given to ergonomic factors, harmonizing walking speed with task demand, and the capability of practice to ameliorate performance decrements-particularly in typing. 


\section{REFERENCES}

1. Booth FW, Gordon SE, Carlson, CJ, Hamilton, MT. Waging war on modern chronic diseases: primary prevention through exercise biology. J Appl Physiol. 2000;88(2):774-787.

2. National Diabetes Data Group and National Institute of Diabetes and Digestive and Kidney Diseases (2005). Diabetes in America (2 ${ }^{\text {nd }}$ ed.). Bethesda, Md: National Institutes of Health, National Institute of Diabetes and Digestive and Kidney Diseases.

3. Healthy People 2010. Leading health indicators: priorities for action. Available online at: http://www.healthypeople.gov/LHI/Priorities.htm. Accessed March 1, 2009.

4. U.S. Department of Health and Human Services (1996). Surgeon General's report on physical activity and health. Available online at: http://www.health.gov/paguidelines/ pdf/paguide.pdf. Accessed March 1, 2009.

5. U.S. Centers for Disease Control and Prevention. Prevalence of regular physical activity among adults-United States, 2001 and 2005. MMWR Morb Mortal Wkly Rep. 2007;56(46):1209-1212.

6. Hurley BF; Hagberg JM; Goldberg AP; Seals DR; Ehsani AA; Brennan RE; Holloszy JO. Resistive training can reduce coronary risk factors without altering VO2max or percent body fat. Med Sci Sports Exerc. 1988;20(2):150-154.

7. Blair SN, Brodney S. Effects of physical inactivity and obesity on morbidity and mortality: current evidence and research issues. Med Sci Sports Exerc. 1999;31(11) (Suppl 1):S646S662.

8. Thompson JL, Exercise in improving health v. performance. Proc Nutr Soc. 2009;68(1):2933.

9. Haskell WL, Lee IM, Pate RR, Powell KE, Blair SN, Franklin BA, et al. Physical activity and public health: updated recommendations for adults from the American College of Sports Medicine and the American Heart Association. Med Sci Sports Exerc. 2007;39(8):14231434.

10. U.S. Department of Health and Human Services. 2008 physical activity guidelines for Americans. Available online at: http://www.health.gov/paguidelines/guidelines/ default.aspx\#toc. Accessed March 1, 2009.

11. Pate RR, O’Neill JR, Lobelo F. The evolving definition of "sedentary." Exerc Sport Sci Rev. 2008; 36(4):173-178. 
12. Healy GN, Dunstan DW, Salmon, J, Shaw JE, Zimmet, PZ, Owen N. Televison time and continuous metabolic risk in physically active adults. Med Sci Sports Exerc. 2008;40(4):639645.

13. Bey L and Hamilton MT. Suppression of skeletal muscle lipoprotein lipase activity during physical inactivity: a molecular reason to maintain daily low-intensity activity. J Physiol. 2003;551(2):673-682.

14. Zderic TW and Hamilton MT. Physical inactivity amplifies the sensitivity of skeletal muscle to the lipid-induced downregulation of lipoprotein lipase activity. J Appl Physiol. 2006;100:249-257.

15. Wittrup HH, Tybjærg-Hansen A, Nordestgaard, B. Lipoprotein lipase mutations, plasma lipids and lipoproteins, and risk of ischemic heart disease: a meta-analysis. Circulation. 1999;99(22):2901-2907.

16. Hamilton MT, Hamilton DG, Zderic TW. Role of low energy expenditure and sitting in obesity, metabolic syndrome, type 2 diabetes, and cardiovascular disease. Diabetes. 2007;56(11):2655-2667.

17. King GA, Fitzhugh EC, Bassett, DR, McLaughlin JE, Strath, SJ, Swartz AM, et al. Relationship of leisure-time physical activity and occupational activity to the prevalence of obesity. Int J Obes. 2001;25(5):606-612.

18. Green BB, Cheadle A, Pellegrini AS, Harris JR. Active for life: a work-based physical activity program. Prev Chronic Dis. 2007;4(3):A63.

19. Kruger J, Yore MM, Bauer DR, Kohl HW. Selected barriers and incentives for worksite health promotion services and policies. Am J Health Promot. 2007;21(5):439-447.

20. Levine J, Miller JM. The energy expenditure of using a "walk-and-work" desk for office workers with obesity. Br J Sports Med. 2007;41:558-561

21. Edelson N, inventor. Adjustable portable exercise desk. US Patent 5,257,701. November 2 1993.

22. Edelson N, Danoff J. Walking on an electric treadmill while performing office work. SIGCHI Bulletin.1989;21(1), 72-77.

23. John D, Bassett DR, Thompson, DL, Fairbrother JT, Baldwin DR, et al. Treadmill workstation use and work performance. J Phys Act Health. In press. 
24. Beauchet O, Dubost V, Herrman FR, Kressig RW. Stride to stride variability while backward counting among healthy young adults. J Neuroeng Rehabil. 2005;2(26).

25. Regnaux JP, Robertson J, Smail DB, Daniel O, Bussel B. Human treadmill walking needs attention. J Neuroeng Rehabil. 2006;3(19).

26. Lajoie Y, Barbeau H, Hamelin M. Attentional requirements of walking in spinal cord injured patients compared to normal participants. Spinal Cord. 1999;37:245-250.

27. Abernethy, B., Hanna, H., \& Plooy, A. (). The attentional demands of preferred and nonpreferred gait patterns. Gait Posture, 2002;15:256-265.

28. Mitrushina M, Boone KB, Razani J, D’Elia LF. Handbook of Normative Data for NeuropsychologicaL Assessment. $2^{\text {nd }}$ Ed. New York: Oxford University Press; 2005:134-139.

29. Mitrushina M, Boone KB, Razani J, D’Elia LF. Handbook of Normative Data for NeuropsychologicaL Assessment. $2^{\text {nd }}$ Ed. New York: Oxford University Press; 2005:108-133.

30. Golden CJ, Freshwater SM. Stroop Color and Word Test: A Manual for Clinical and Experimental Uses. Wood Dale, IL.: Stoelting Co.;2002

31. Mitrushina M, Boone KB, Razani J, D'Elia LF. Handbook of Normative Data for NeuropsychologicaL Assessment. $2^{\text {nd }}$ Ed. New York: Oxford University Press; 2005:419-433.

32. Mitrushina M, Boone KB, Razani J, D’Elia LF. Handbook of Normative Data for Neuropsychological Assessment. $2^{\text {nd }}$ Ed. New York: Oxford University Press; 2005:420.

33. Klapp ST, Hill MD, Tyler JG, Martin ZE, Jagacinski RJ, Jones MR. On marching to two different drummers: perceptual aspects of the difficulties. J Exp Psychol Hum Percept. $1985 ; 11(6): 814-827$. 